\title{
PROPOSTA DE PREVENÇÃO DA LARVA MIGRANS ATRAVÉS DA EDUCAÇÃO AMBIENTAL
}

\author{
Joel José Megale Gabrili ${ }^{1}$; Silas Lobo ${ }^{2}$ \\ 1- Biólogo formado pela Universidade Guarulhos - UnG - Guarulhos-sp e-mail: leoj megale@yahoo.com.br \\ 2- Mestre em Biologia Celular Docente da Universidade Guarulhos - UnG - Guarulhos-sp e-mail: \\ slobo@prof.ung.br
}

RESUMO: Alguns nematóides parasitos de cães e gatos, quando infectam o ser humano seguem por um ciclo errático ao invés de se desenvolverem até o estagio adulto, e ficam migrando pelo organismo por um período indeterminado, podendo ocasionar a síndrome de Larva Migrans Visceral ou Ocular quando ingerido o ovo infectante de Toxocara sp., ou então a síndrome de Larva Migrans Cutânea quando larvas infectantes de Ancylostoma sp. penetram ativamente pela pele. Um método barato e eficaz de prevenir a população de tais zoonoses é a Educação Ambiental, informando, sensibilizando e conscientizando sobre as formas de contagio e profilaxia dessas síndromes.

\section{INTRODUÇÃO}

Praças públicas contaminadas com fezes de cães e gatos são consideradas um problema de Saúde Pública, devido ao seu potencial zoonótico. Principalmente a larva migrans visceral (LMV), causada por Toxocara sp. e a larva migrans cutânea (LMC), causada por Ancylostoma sp. (CÔRTES et al., 1988; ARAÚJO et al., 1999; NUNES et al,. 2000; RAGOZO et al., 2002; CASTRO et al., 2005).

A infecção por Toxocara sp. ocorre através da ingestão de ovos larvados de $T$. canis ou $T$. catis geralmente encontrados no solo. E como outros nematódeos de animais que infectam ocasionalmente o homem, este parasita não completa seu ciclo de vida no ser humano, causando a LMV e permanecendo principalmente no fígado, nos pulmões, no cérebro, nos olhos e nos linfonodos (ARAÚJO et al., 1999; SCAINI et al., 2003; GUIMARÃES et al., 2005; REY, 2010).

Já a LMC é causada pela penetração de larvas filarioides encontradas no solo, principalmente de $A$. braziliensis e $A$. caninum, que parasitam cães e gatos e não conseguem completar sua evolução na espécie humana, invadindo e permanecendo na pele por algum tempo, abrindo túneis na epiderme e produzindo uma dermatite conhecida vulgarmente como "bicho geográfico". Ocorrendo principalmente nos pés, e nas mãos e nádegas de crianças que brincam com solos contaminados, como caixas de areia de parques e praias (ARAÚJO et al., 1999; NUNES et al,. 2000; SCAINI et al., 2003; SANTARÉM et al,. 2004; CASTRO et al., 2005; GUIMARÃES et al., 2005; REY, 2010).

Por falta de informação, as pessoas não se importam de levar seus animais a poluírem com fezes as ruas, praças e praias. Onde os ovos sempre muito abundantes, sobrevivem por semanas ou meses no solo e nas poeiras. O uso constante de calçados é um dos meios eficientes de prevenção dessa zoonose, e para isso, a população deve compreender as razões pelas quais se requer mudança de hábitos tradicionais, como andar descalço e não recolher as fezes dos animais (CASTRO et al., 2005; GUIMARÃES et al., 2005; REY, 2010). 
Em Guarulhos além dos animais errantes que freqüentam as praças públicas, é comum ver pessoas passeando com seus cães, que muitas vezes defecam e as fezes permanecem por lá. Como também é comum ser visto adultos e crianças no mesmo ambiente, e sabendo das possíveis zoonoses, é importante ser feito um levantamento dos agentes de larva migrans nas fezes encontradas em praças, e através dos resultados, desenvolver uma proposta de educação ambiental.

\section{OBJETIVO}

O presente trabalho tem por objetivo determinar a ocorrência de agentes de larva migrans em fezes de cães e gatos encontradas em praças públicas de Guarulhos, SP e utilizar os resultados para sensibilizar a população sobre possíveis zoonoses.

\section{MATERIAL E MÉTODOS}

\subsection{Levantamento de Dados}

A pesquisa foi desenvolvida no município de Guarulhos, SP, de março a maio de 2011, totalizando 7 coletas em diferentes praças. Com o auxilio de sacos plástico foram coletadas apenas fezes não ressecadas, armazenadas sem conservantes, e transportadas para o laboratório de Biociências da Universidade Guarulhos, onde foram mantidas sob refrigeração e processadas após 24 horas pelo método de Ritchie modificado, então observadas em microscópio óptico para presença de ovos de Toxocara sp. e ovos e larvas de Ancylostoma sp.

\subsection{Proposta de Educação Ambiental}

Através dos resultados obtidos, será proposto palestras com auxilio de data show e duração de 1 hora/aula, explanando sobre as formas de contágio e profilaxia das diferentes síndromes de Larva Migrans, podendo também ser realizada em mais horas/aula com maiores detalhes sobre seus agentes etiológicos. Podendo ser apresentadas em instituições de ensino, empresas privadas e órgãos públicos, para um público variado de crianças e adultos.

\section{RESULTADOS E DISCUSSÃO}

Das 69 amostras coletadas 22 (31,88\%) mostraram-se positivas, sendo 1 (1,45\%) com duplo parasitismo, 8 (11,59\%) com Toxocara sp. e 13 (18,84\%) com Ancylostoma sp..

Chieffi et al., (1976) analisaram em Londrina, PR 158 amostras de fezes de cães domiciliados, sendo 70 (44,30\%) positivas para Toxocara sp., em Botucatu SP Santarém et al., (1998) analisou fezes escolhidas ao acaso, coletadas em praças públicas e encontrou $17,5 \%$ de positividade para Toxocara sp. em um total de 120 amostras analisadas. Segundo Prates et al., (2009) O Toxocara é considerado um dos parasitos mais comuns mundialmente, sua prevalência pode chegar até $81 \%$ da população de cães. 
Ferreira et al., (2009) em Aracaju SE analisou amostras de 150 cães, 50 de cães domiciliados, 50 de cães de um abrigo e 50 de cães errantes apreendidos do Centro de Zoonoses de Aracaju, sendo Ancylostoma sp. e o Toxocara canis os mais encontrados. A porcentagem de positivos para Ancylostoma sp. foi de 40\% (domiciliados), 53,8\% (abrigo), 86,4\% (zoonoses), para Toxocara sp. foi de $20 \%$ (domiciliados), 19,2\% (abrigo) e negativo para este parasito em cães da Zoonoses.

No estudo de Santos et al., (2006) em Guarulhos SP, foram analisadas 166 amostras sendo Ancylostoma sp. encontrado em $10.84 \%$ e Toxocara canis em (1.81\%).

No presente estudo também foi encontrada uma amostra de fezes humana contendo 3 espécies de amebas comensais: Entamoeba coli, lodamoeba butschlli e Endolimax nana, deixando clara a importância de ser feito inquéritos parasitológicos em moradores de rua da cidade, se tratando também questão de saúde pública.

\section{CONCLUSÃO}

- É freqüente o encontro de ovos de Toxocara sp., e ovos e larvas de Ancylostoma sp. em vários estádios de evolução, contaminando praças públicas da zona urbana de Guarulhos.

- Devido esta freqüência é de extrema importância informar a população sobre o risco de possíveis zoonoses em áreas de lazer da cidade, sendo a Educação Ambiental uma excelente ferramenta para tal intervenção.

\section{REFERÊNCIAS BIBLIOGRÁFICAS}

ARAÚJO, F. R. et al. Contaminação de praças públicas de Campo Grande, Mato Grosso do Sul, Brasil, por ovos de Toxocara e Ancylostoma em fezes de cães. Revista da Sociedade Brasileira de Medicina Tropical, Campo Grande, v. 32, n. 3, p. 581-583, set-out. 1999.

CASTRO, J. M.; SANTOS, S. V.; MONTEIRO, N. A. Contaminação de canteiros da orla marítima do Município de Praia Grande, São Paulo, por ovos de Ancylostoma e Toxocara em fezes de cães. Revista da Sociedade Brasileira de Medicina Tropical, São Paulo, v. 38, n. 2, p. 199-201, mar-abr. 2005.

CHIEFFI, P. P.; MULLER, E. E. Prevalência de parasitismo por Toxocara canis em cães e presença de ovos de Toxocara sp. no solo de localidades públicas da zona urbana do município de Londrina, estado do Paraná, Brasil. Rev Saúde públ., São Paulo, v. 10, p. 367-72, 1976.

CÔRTES, V. A.; PAIM, G. V.; FILHO, R. A. A. Infestação por Ancilostomídeos e Toxoçarídeos em Cães e Gatos Apreendidos em Vias Públicas, São Paulo (Brasil). Rev Saúde públ., São Paulo, v. 22, n. 4, p. 341-3, 1988.

FERREIRA, M. A. S. et al. Avaliação de endoparasitos em cães domiciliados, de abrigo e errantes na cidade de Aracaju - Sergipe. Medicina Veterinária, Recife, v. 3, n. 3, p. 20-5, jul./set., 2009.

GUIMARÃES, A. M. et al. Ovos de Toxocara sp. e larvas de Ancylostoma sp. em praça pública de Lavras, MG. Rev Saúde públ., Lavras, v. 32, n. 2, p. 293-5, 2005. 
NUNES, C. M. et al. Ocorrência de larva migrans na areia de áreas de lazer das escolas municipais de ensino infantil, Araçatuba, SP, Brasil. Rev Saúde públ., Araçatuba, v. 34, n. 6, p. 656-8, 2000.

PRATES, L. et al. Freqüência de parasitos intestinais em cães domiciliados da cidade de Maringá, PR. Arq Brás Med Vet Zootec., v. 61, n. 6, p. 1468-1470, 2009.

RAGOZO, A. M. A. et al. Ocorrência de parasitos gastrintestinais em fezes de gatos das cidades de São Paulo e Guarulhos. Braz J vet Res anim Sci., São Paulo, v. 39, n. 5, p. 244-6, 2002.

REY, L. Bases da Parasitologia Médica. 3 ed. Rio de Janeiro: Guanabara Koogan, 2010.

SANTARÉM, V. A.; GIUFFRIDA, R.; ZANIN, G. A. Larva migrans cutânea: ocorrência de casos humanos e identificação de larvas de Ancylostoma spp em parque público do município de Taciba, São Paulo. Revista da Sociedade Brasileira de Medicina Tropical, Presidente Prudente, v. 37, n. 2, p. 179-181, mar-abr. 2004.

SANTOS, S. V.; CASTRO, J. M. Ocorrência de agentes parasitários com potencial zoonótico de transmissão em fezes de cães domiciliados do município de Guarulhos, SP. Arq Inst Biol., v. 73, n. 2, p. 255-7, abr./jun., 2006.

SCAINI, C. J. et al. Contaminação ambiental por ovos e larvas de helmintos em fezes de cães na área central do Balneário Cassino, Rio Grande do Sul. Revista da Sociedade Brasileira de Medicina Tropical, Rio Grande, v. 36, n. 5, p. 617-9, set-out. 2003. 